rate of preoperative moderate to severe anemia and potential for improvement. This represents an opportunity for patientsafety initiatives.

\section{EPV270/\#88 OPTIMIZING THE SCREENING AND MANAGEMENT OF PREOPERATIVE ANEMIA PRIOR TO GYNECOLOGIC ONCOLOGY SURGERY (OPRA): A QUALITY IMPROVEMENT INITIATIVE}

${ }^{1} E$ Spenard*, ${ }^{2} Y$ Lin, ${ }^{3} \mathrm{~A}$ Covens, ${ }^{3} \mathrm{~L}$ Gien, ${ }^{2} \mathrm{~J}$ Callum, ${ }^{2} \mathrm{R}$ Tano, ${ }^{2} \mathrm{~S}$ Jadunandan, ${ }^{4} \mathrm{P}$ Trbovich, ${ }^{3} \mathrm{D}$ Vicus. ${ }^{1}$ University of Toronto, Gynecologic Oncology, Toronto, Canada; ${ }^{2}$ Sunnybrook Health Sciences Center, Laboratory Medicine and Molecular Diagnostics, Toronto, Canada; ${ }^{3}$ Sunnybrook Health Sciences Centre, Gynecologic Oncology, Toronto, Canada; ${ }^{4}$ University of Toronto, Institute of Health Policy, Management and Evaluation, Toronto, Canada

\subsection{6/ijgc-2021-IGCS.341}

Objectives Preoperative anemia is an established negative prognostic factor in gynecologic oncology patients. However, it is often undetected and inadequately treated. The aim of this quality-improvement initiative was to increase the treatment rate of preoperative anemia in gynecologic oncology patients undergoing surgery at a large tertiary centre.

Methods This was a time-series study between October 1, 2019-April 1, 2021. All gynecologic oncology patients consented for surgery at our institution were included. From October to December 2020, three interventions were implemented: a tracking system for patients consented for surgery, standardized screening for preoperative anemia, and automatic referral to patient blood management program(PBMP). The primary outcome was the treatment rate of patients with anemia receiving intravenous iron or erythropoiesis-stimulating agent prior to surgery. Secondary outcomes were perioperative blood transfusion rate, postoperative nadir hemoglobin $(\mathrm{Hb})$ level and length of stay(LOS). Process measures included screening and PBMP referral rates. Balancing measures included treatment complications and patient satisfaction.

Results of the 151 pre-intervention and 229 post-intervention patients, $32 \%(n=121)$ had anemia. After intervention, screening rates and PBMP referral rates increased from $2 \%$ to $82 \%(\mathrm{p}<0.00001)$ and $9 \%$ to $80 \%(\mathrm{p}<0.00001)$, respectively. The treatment rate increased from $7 \%$ to $31 \%(\mathrm{p}<0.009)$. The transfusion rate decreased from $20 \%$ to $12 \%(\mathrm{p}=0.027)$. The postoperative nadir $\mathrm{Hb}$ level increased from 92 to $96 \mathrm{~g} / \mathrm{L}$ $(p=0.049)$. There was no difference in LOS across all surgeries. No treatment associated complications were reported. The median patient satisfaction score was 4.5 on a five-point Likert scale.

Conclusions Optimizing treatment of preoperative anemia in gynecologic oncology patients significantly decreased transfusion rate, without affecting LOS.

\section{EPV271/\#98 EFFECT OF SURGICAL MODALITY ON THE OCCURRENCE OF VAGINAL VAULT DEHISCENCE}

${ }^{1}$ YJ Lee*, ${ }^{2}$ KJ Eoh, ${ }^{1}$ Y-N Kim, ${ }^{1}$ YJ Rhee, ${ }^{3}$ YJ Lee, ${ }^{3}$ J-Y Lee, ${ }^{3}$ EJ Nam, ${ }^{3}$ SW Kim, ${ }^{3}$ S Kim, ${ }^{3} Y \mathrm{~T}$ Kim. ' ${ }^{1}$ Severance hospital, Obstetrics and Gynecology, Seoul, Korea, Republic of; ${ }^{2}$ Yongin Severance hospital, Obstetrics and Gynecology, Gyeonggido, Korea, Republic of;

${ }^{3}$ Yonsei University College of Medicine, Dept. of Ob/gyn, Seoul, Korea, Republic of
Objectives This study aimed to analyze the incidence and risk factors of vault dehiscence after hysterectomy with respect to the mode of operation and the time to occurrence.

Methods We conducted a retrospective study including 6,530 patients who underwent hysterectomy at Severance Hospital

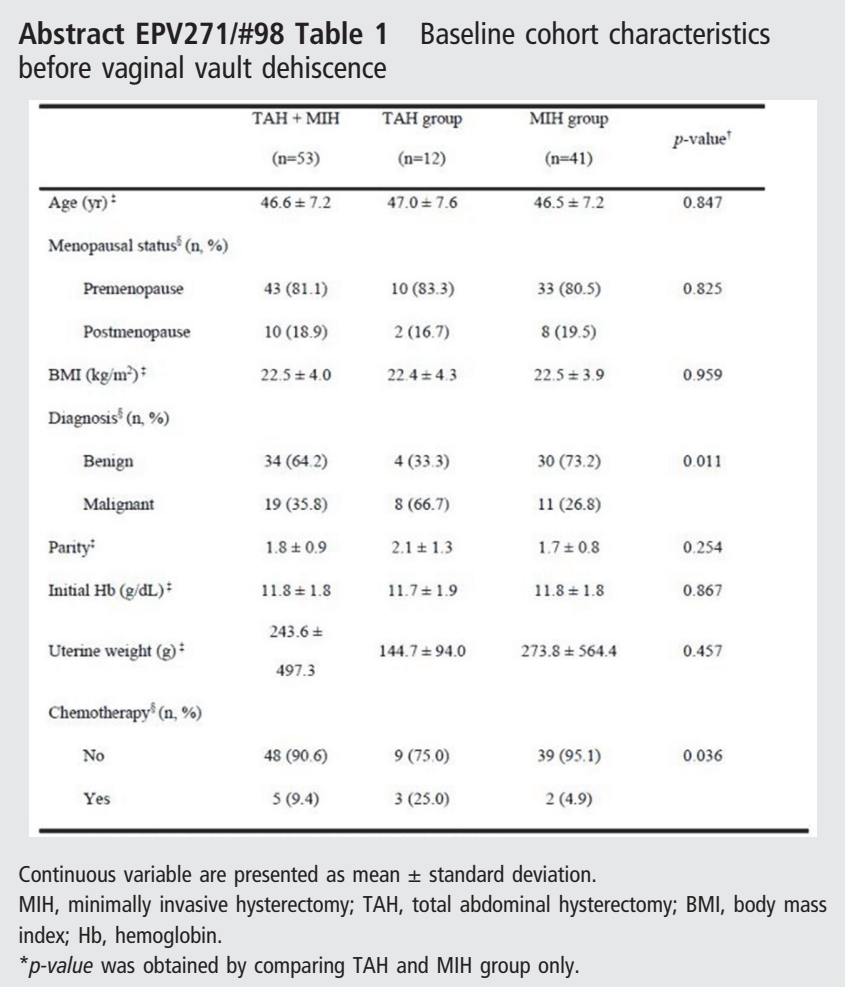

Abstract EPV271/\#98 Table 2 Comparison between early and late occurrence in patients with vaginal vault dehiscence

\begin{tabular}{|c|c|c|c|}
\hline & $\begin{array}{c}\text { Early occurrence } \\
<8 \text { weeks }\end{array}$ & $\begin{array}{l}\text { Late occurrence } \\
\geq 8 \text { weeks }\end{array}$ & $p$-value \\
\hline \multicolumn{4}{|l|}{ Baseline cohort characteristics } \\
\hline $\operatorname{Age}(\mathrm{yr})$ & $45.3 \pm 1.3$ & $48.3 \pm 1.5$ & 0.130 \\
\hline \multicolumn{4}{|l|}{ Menopausal status } \\
\hline Premenopause & $27(93.1)$ & $16(66.7)$ & 0.031 \\
\hline Postmenopause & $2(6.9)$ & $8(33.3)$ & \\
\hline BMI $\left(\mathrm{kg} / \mathrm{m}^{2}\right)$ & $23.2 \pm 0.8$ & $21.6 \pm 06$ & 0.123 \\
\hline Uterine weight (g) & $322.3 \pm 645.2$ & $137.3 \pm 91.2$ & 0211 \\
\hline \multicolumn{4}{|l|}{ Diagnosis } \\
\hline Benign & $18(62.1)$ & $16(66.7)$ & 0.728 \\
\hline Malignant & $11(379)$ & $8(33.3)$ & \\
\hline \multicolumn{4}{|l|}{ Chemotherapy } \\
\hline No & $26(89.7)$ & $22(21.7)$ & 1.000 \\
\hline Yes & $3(10.3)$ & $2(8.3)$ & \\
\hline \multicolumn{4}{|l|}{ Mode of hysterectomy } \\
\hline Minimally invasive surgery & $21(72.4)$ & $20(83.3)$ & 0.344 \\
\hline Open & $8(27.6)$ & $4(167)$ & \\
\hline \multicolumn{4}{|l|}{ Management after vaginal vault dehiscence } \\
\hline \multicolumn{4}{|l|}{ Surgical repair ${ }^{\top}$} \\
\hline Yes & $15(517)$ & $23(95.8)$ & 0.000 \\
\hline No & $14(48.3)$ & $1(4.2)$ & \\
\hline \multicolumn{4}{|l|}{ Method of dehiscence repair } \\
\hline Minimally invasive surgery & $2(6.9)$ & $13(54.2)$ & 0.000 \\
\hline Open & $1(3.4)$ & $1(4.2)$ & \\
\hline Vaginal & $12(41.4)$ & $9(37.5)$ & \\
\hline Embolization & $1(3.4)$ & $0(0.0)$ & \\
\hline Conservative & $13(44.8)$ & $1(4.2)$ & \\
\hline Hospitalized days after dehiscence (day) & $7.1 \pm 5.2$ & $49 \pm 2.6$ & 0.149 \\
\hline
\end{tabular}

Continuous variable are presented as mean \pm standard deviation. BMI, body mass index; MIS, minimally invasive surgery. tSurgical repair includes Minimally invasive surgery, Open and vaginal approach for repair. 
between July 2013 and February 2019. We then analyzed the characteristics of 53 cases of vaginal vault dehiscence based on the mode of hysterectomy and the time to occurrence.

Results Among 6,530 hysterectomy cases, 53 cases of vault dehiscence $(0.81 \%)$ were found, with 41 occurring after total abdominal hysterectomy (TAH) $(0.46 \%)$ and 12 occurring after minimally invasive hysterectomy (MIH) (1.05\%) $(p=0.009)$. The incidence of dehiscence after MIH was statistically higher in benign diseases. In contrast, a malignant disease was associated with a higher risk of dehiscence after TAH $(p=0.011)$. The time to occurrence, based on the 8weeks cutoff, varied significantly based on the menopausal status; early-onset dehiscence occurred more frequently in premenopausal compared to postmenopausal women $(93.1 \%$ vs. $33.3 \%$, respectively; $\mathrm{p}=0.031)$. Surgical repair was more frequently required in cases of late-onset dehiscence than in early-onset dehiscence $(95.8 \%$ vs. $51.7 \%$, respectively; $\mathrm{p}<0.001$ ).

Conclusions Our results were consistent with the concept that the occurrence of vaginal vault dehiscence may be correlated with the method of surgery. Patient-specific factors, such as menopausal status, uterine weight, and cause of operation, may influence the timing and severity. Thus, personalized counseling may help reduce vaginal vault dehiscence.

\section{EPV272/\#115 SCALP COOLING FOR REDUCING ALOPECIA IN GYNECOLOGY ONCOLOGY PATIENTS TREATED WITH DOSE-DENSE CHEMOTHERAPY: A PILOT PROJECT}

${ }^{1} \mathrm{C}$ Mitric*, 'B How, ${ }^{1} \mathrm{E}$ Matanes, ${ }^{1} \mathrm{Z}$ Amajoud, ${ }^{2} \mathrm{H}$ Zaaroura, ${ }^{3} \mathrm{H}-\mathrm{H}$ Nguyen, ${ }^{1} \mathrm{~N}$ Drummond, ${ }^{1} S$ Salvador, 'W Gotlieb, 'S Lau. 'McGill University, Jewish General Hospital, Gynecology Oncology, Montreal, Canada; ${ }^{2}$ Rambam Health Care Campus, Department of Dermatology, Haifa, Israel; ${ }^{3}$ Medi-Soleil Centre, Department of Dermatology, St-Jean-sur-Richelieu, Canada

10.1136/ijgc-2021-IGCS.343

Objectives To determine the efficacy of scalp cooling for the prevention of chemotherapy-induced alopecia specifically in the gynecology oncology patient population.

Methods This prospective pilot study included patients diagnosed with a gynecological malignancy that received Digni$\mathrm{Cap}^{\mathrm{TM}}$ scalp cooling. Patients were divided into two groups based on chemotherapy regimen: Carboplatin with area under the curve (AUC) 5-6 every three weeks and (1) conventional Paclitaxel $175 \mathrm{mg} / \mathrm{m}^{2}$ every three weeks or (2) Paclitaxel 80 $\mathrm{mg} / \mathrm{m}^{2}$ weekly. A 1-10 visual analogue scale (1- no hair loss, 10- complete hair loss) was used to assess degree of hair loss by patients themselves and by a certified dermatologist using photographs. Changes in quality of life and body image were measured using the European Organization for Research and Treatment of Cancer quality of life questionnaire version 3 (EORTC QLQ-C30) and the Body Image Scale (BIS) for cancer patients.

Results Hair preservation occurred with use of a scalp cooling device for patients receiving weekly Paclitaxel $(n=20)$, but not conventional every three weeks Paclitaxel $(n=8)$. Ten of 15 patients $(66.7 \%)$ in the dose-dense group lost less than $50 \%$ of their hair based on self-assessment and 14 of 16 (87.5\%) based on dermatologist assessment. No patient in this group acquired a wig. The quality of life (QoL) scoring had a trend towards worse QoL in the dose-dense group with a trend towards better BIS scores.

Conclusions Scalp cooling may allow for hair preservation in gynecology oncology patients receiving carboplatin AUC 5-6 and weekly paclitaxel $80 \mathrm{mg} / \mathrm{m}^{2}$ combination chemotherapy.

\section{EPV273/\#268 AUDIT OF COMPLICATIONS IN GYNAECOLOGICAL ONCO-SURGERIES AT A TERTIARY CARE HOSPITAL IN SOUTH INDIA}

${ }^{1} \mathrm{P}$ Veena*, ${ }^{2} \mathrm{R}$ Sirisha, ${ }^{3} \mathrm{P}$ Penumadu. 'Jawaharlal Institute of Postgraduate Medical Education and Research, Obstetrics and Gynecology, Puducherry, India; ${ }^{2}$ IIPMER, Obgyn, Puducherry, India; ${ }^{3}$ IIPMER, Surgical Oncology, Puducherry, India

\subsection{6/ijgc-2021-IGCS.344}

Objectives Complications are an inherent part of surgical procedures, more so in onco-surgeries given the radicality of the procedures. Negative outcomes must be audited and classified to find more specific targets for quality improvement. Our primary objective was to study the complications of gynecological onco-surgeries graded according to the Clavien-Dindo grading system. The secondary objective was to evaluate the association between perioperative risk factors and complications of gynecological onco-surgeries.

Methods A cohort of 157 patients who underwent onco-surgeries in a tertiary care center in South India was studied from August 2017 to May 2019. Patients diagnosed with benign lesions by histopathology post-operatively and patients who are not willing to participate in the study were excluded. Post-operative complications were noted and graded according to the Clavien-Dindo grading system.

Results Among a cohort of 157 patients who underwent gynecological onco-surgeries, a complication rate of around $41.1 \%$ is observed. Majority of these complications were grade 1 $(n=43,27.3 \%)$, grade $2(n=34,21.6 \%)$ or grade $3 A(n=27$, 17.2\%). Severe complications, i.e., $>$ Grade $3 \mathrm{~b}$, were observed in around $8.2 \%$ of the study patients. Vulvar cancer patients had the highest complication rate of around 80\% (all grade 3B complications). Among the intra-operative characteristics, only the complexity of the surgery showed statistical association with postoperative complications $(p=0.04)$.

Conclusions Higher grade of complications according to the Clavien-Dindo grading system was significantly associated with duration of hospital stay.

\section{EPV274/\#367 MALIGNANCY-ASSOCIATED BOWEL OBSTRUCTION: OUTCOMES \& EVALUATION OF THE HENRY SCORE}

E Howell*, C Watson, A Puechl, A Alvarez Secord, B Davidson. Duke University Medical Center, Obstetrics and Gynecology, Durham, USA

\subsection{6/ijgc-2021-IGCS.345}

Objectives Malignant bowel obstruction (MBO) represents a devastating sequelae of gynecologic cancer. The Henry Score was developed to predict 30-day mortality and identify candidates for surgical management of MBO. The initial study only included 25\% gynecologic patients, and this score has never been validated in a gynecologic cohort. Our objectives were to 